\title{
Benchmarking of Grid Fault Modes in Single-Phase Grid-Connected Photovoltaic Systems
}

\author{
Yongheng Yang, Frede Blaabjerg \\ Department of Energy Technology \\ Aalborg University \\ Pontoppidanstraede 101, Aalborg, DK-9220 Denmark \\ yoy@et.aau.dk,fbl@et.aau.dk
}

\author{
Zhixiang Zou \\ School of Electrical Engineering \\ Southeast University \\ No. 2 Sipailou, Nanjing, 210096 China \\ zou.zhixiang@seu.edu.cn
}

\begin{abstract}
Pushed by the booming installations of single-phase photovoltaic (PV) systems, the grid demands regarding the integration of PV systems are expected to be modified. Hence, the future PV systems should become more active with functionalities of low voltage ride-through (LVRT) and the grid support capability. The control methods, together with grid synchronization techniques, are responsible for the generation of appropriate reference signals in order to handle ride-through grid faults. Thus, it is necessary to evaluate the behaviors of grid synchronization methods and control possibilities in single phase systems under grid faults.

The intent of this paper is to present a benchmarking of grid fault modes that might come in future single-phase PV systems. In order to map future challenges, the relevant detection and control strategies are discussed. Some faulty modes are studied experimentally and provided at the end of this paper. It is concluded that there are extensive control possibilities in singlephase PV systems under grid faults. The Second Order General Integral based PLL technique might be the most promising candidate for future single-phase PV systems because of its fast adaptive-filtering characteristics and is able to full fill future standards.
\end{abstract}

\section{INTRODUCTION}

The installation of single-phase PV systems has really been booming in recent years because of the matured PV technology and the declined price of PV panels [1]. Pushed by the high penetration of renewable energy systems, many grid requirements have been released in order to regulate interconnected renewable power generation [2]-[6]. Some basic requirements are defined in the grid regulations, like power quality, frequency stability and voltage stability [7], and even more specific demands for wind turbines have been issued [4].

Nowadays, the thriving scenario of large-scale gridconnected single-phase PV systems has raised concern about its effect on the stability and availability of the public grids [8]-[10]. Therefore, reasonably technical requirements are expected to be put forward as an improvement for such an integration. Like the grid requirements for wind turbines, the future grid-connected single-phase PV systems should not only maintain the stability and quality of the grid, but also have

Part of this work was presented on the $3^{\text {rd }}$ International Symposium on Power Electronics for Distributed Generation Systems, PEDG 2012. some ancillary functionalities, such as reactive power support and Fault Ride Through (FRT) capability [11]-[15]. It can be foreseen that in the near future the grid-connected PV systems will become more active and more "smart" with such functionalities.

In that case, the control methods should be ready for single-phase PV applications, because they are responsible for generating appropriate reference signals in order to handle ride-through grid faults, which means an evaluation and benchmarking of possible control strategies for single-phase applications are necessary. Practically, the single-phase $P Q$ theory [16], [17] could be adopted in the control systems. By regulating the maximum power point, the active power could be controlled within the boundaries in order to avoid over-current tripping under grid voltage sags. Furthermore, the droop control methods could be used to adjust the active and reactive powers as reported in [18], [19].

Moreover, as the prerequisite of a good control, the synchronization technique for single-phase PV systems has also become of high interest. Recent research demonstrates that the phase locked loop (PLL) based synchronization methods need to have more attention [4], [6], [20]-[24]. Among these, the adaptive mechanism based synchronization techniques gain more attractiveness because of their high robustness and fast response characteristics. Such kinds of methods may be the best candidates for single-phase PV systems operating in faulty-grid modes. However, it may also cause undesired influences, which have been discussed in [25].

The objective of this paper is to study the performance of single-phase grid-connected PV systems under grid faults defined by the basic grid codes of wind turbine systems. Firstly, an overview of the existing grid requirements is given. Particular attention is paid on the possible control strategies which will help the single-phase PV systems to handle ridethrough utility faults or operate under abnormal grid conditions. It is followed by an evaluation of the synchronization methods. Finally, faulty cases are simulated and tested.

\section{Overview of SElected GRID REQuirements}

One essential basis of the design and control for gridconnected PV inverters is the grid requirements. Suggestions in some international regulations address that PV inverters should 
disconnect from the utility grid in the presence of abnormal grid conditions in terms of voltage and frequency at the point of common coupling (PCC). This kind of requirements, including islanding protection, are designed on a basis of lowvoltage applications and are set to ensure the safety of utility maintenance personnel and also the public grid.

Considering the impact of large-scale PV systems in the networks to which they are connected, these grid requirements are supposed to be revised or extended with some combined standardized features as well as custom demands. Several European countries have done this for distributed energy resources, especially wind turbine power systems, connected to medium- or high-voltage networks. For instance, the German grid code requires that the distributed power systems connected to the medium- or high-voltage networks should have the capabilities of low voltage ride-through (LVRT) and grid support functionality during grid faults [2], [3].

Different LVRT curves of a defined stay-connected time are presented in Fig. 1. As it is noticed in Fig. 1 that the generation systems required in the German grid code should be capable of riding through 0.15 seconds when the grid voltage amplitude presents a drop to $0 \mathrm{~V}$ and inject some reactive current into the grid. The required reactive current to support the voltage in the German grid regulation is shown in Fig. 2, and it can be given as,

$$
I_{Q}=\left\{\begin{array}{cc}
k \cdot \frac{U-U_{0}}{U_{N}} \cdot I_{N}+I_{Q 0}, & U \geqslant 0.5 \text { p.u. }, k \geqslant 2 \\
-I_{N}+I_{Q 0}, & U<0.5 \text { p.u. }
\end{array}\right.
$$

where $U, U_{0}$, and $U_{N}$ are instantaneous voltage, initial voltage before grid faults and the nominal voltage, and $I_{N}, I_{Q 0}$ are the nominal current and the reactive current before a grid failure.

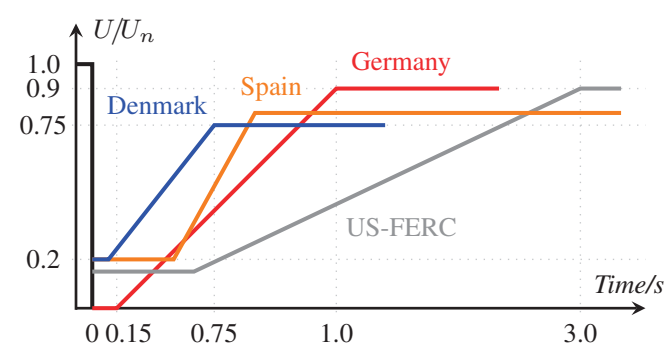

Fig. 1. Low voltage ride-through requirements of wind power systems of different countries [2].

It can be predicted that the above regulations will be recommended to be used for large-scale low-voltage PV systems [10]-[12]. Similar to wind turbine power generations connected to the medium- and high voltage levels, single-phase PV generation systems supplying low-voltage networks in the future will have to make a contribution to network support due to the much higher penetration of PV generation systems connected to the low-voltage grids.

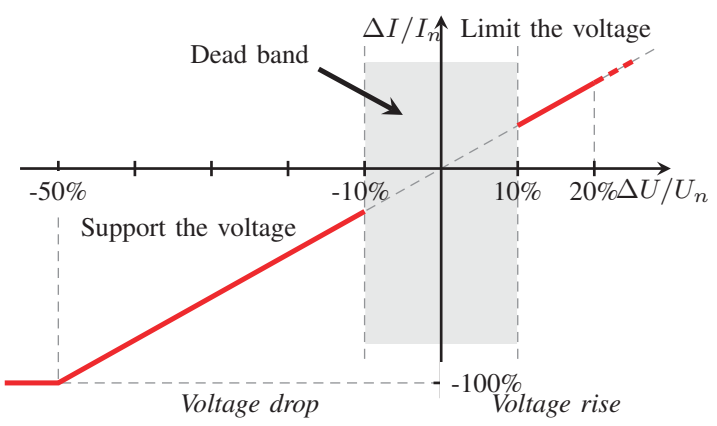

Fig. 2. Voltage support requirements in the event of grid faults for wind turbines [3].

\section{Control Possibilities Under Grid FAults}

The traditional control strategy applied to the single-phase converter system includes two cascaded loops: an inner current loop which has the responsibility for power quality issues and current protection [4], [6], [26] and an outer voltage control loop. In such case it is possible to add control methods into this current loop in single-phase systems in grid faulty mode operations. The overall structure of a single-phase gridconnected PV system is given in Fig. 3.

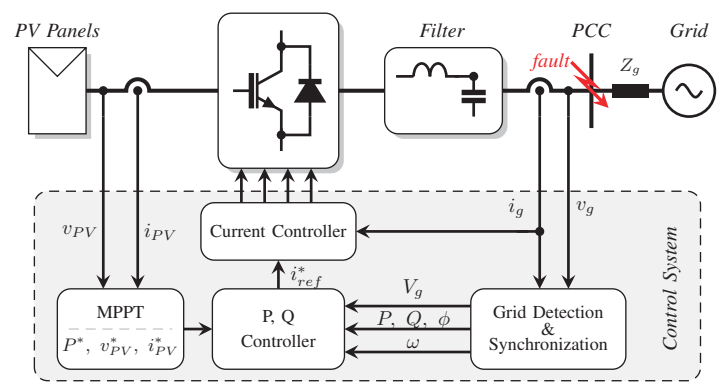

Fig. 3. Overall control structure of a single-phase grid-connected photovoltaic system.

In respect to the control of a three-phase system under grid faults, four major methods are reported in the literature: unity power factor control, positive sequence control, constant active power control and constant reactive power control [6], [26]. These methods are not suitable for single-phase applications since it is difficult to employ directly a $d q$-rotating synchronous reference frame.

One possible solution to the single-phase case is inspired by the Orthogonal Signal Generator (OSG) based PLL principle [4], [6], [26]. According to the single-phase active and reactive power theory [16], [17], the components, $v_{\alpha}$ and $v_{\beta}$, generated by the OSG structure can be used to calculate the active power and reactive power as given by,

$$
\left\{\begin{array}{l}
P=\frac{1}{2}\left(v_{\alpha} i_{\alpha}+v_{\beta} i_{\beta}\right) \\
Q=\frac{1}{2}\left(v_{\beta} i_{\alpha}-v_{\alpha} i_{\beta}\right)
\end{array}\right.
$$

where $\boldsymbol{i}_{\alpha \beta}, \boldsymbol{v}_{\alpha \beta}$ are the grid current and voltage in the $\alpha \beta$ system, and $P, Q$ are the active and reactive powers 
respectively. Thus by this mean, the current reference can be generated as it can be expressed by,

$$
\left\{\begin{array}{l}
i_{\alpha}^{*}=\frac{2\left(v_{\alpha} P^{*}+v_{\beta} Q^{*}\right)}{v_{\alpha}^{2}+v_{\beta}^{2}} \\
i_{\beta}^{*}=\frac{2\left(v_{\beta} P^{*}-v_{\alpha} Q^{*}\right)}{v_{\alpha}^{2}+v_{\beta}^{2}}
\end{array}\right.
$$

in which ' $*$ ' denotes the reference signal. Then the detailed control diagram based on the single-phase $P Q$ theory and the OSG concept can be illustrated as it is shown in Fig. 4.
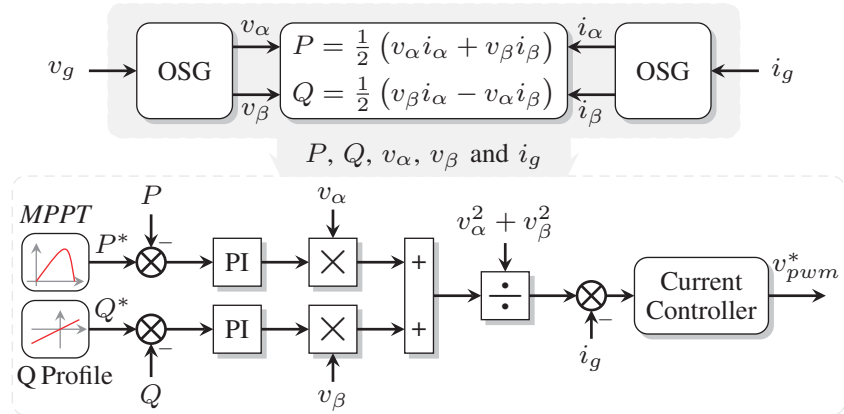

Fig. 4. Control diagram of single-phase systems under grid faults based on the single-phase $P Q$ theory and the orthogonal signal generator concept.

Notably, in this control system, the existing current control methods, such as Proportional Resonant (PR), Deadbeat control (DB), Repetitive controller (RC) and Proportional Integral control (PI) which need a Park Transform $(\alpha \beta \rightarrow d q)$, can be adopted in faulty grid cases. The "Q Profile" shown in Fig. 4 is in compliance with the grid code as described by (1) and in Fig. 2. The reference reactive power $Q^{*}$ is generated according to the voltage sag depth detected by the synchronization units, which means that the "Q Profile" is triggered by the detected voltage amplitude $V_{g}$. Moreover, by employing the Park Transform to the current injected into the grid, the DC quantities of the current are obtained in the rotating synchronous reference frame, leading to the possible use of a basic PI-controller for current regulation or power control [17], [27], [28].

Another control possibility is based on the concept of the frequency and voltage droop control through active and reactive powers, respectively. A droop control method could be adopted to adjust the active and reactive powers in singlephase applications under grid faults. It can be illustrated using the simplified grid-connected PV system as shown in Fig. 5.

On the basis of the assumptions that the line impedance is mainly inductive $\left(X_{l} \gg R_{l}\right)$ and the power angle $\phi$ is very small, the active power $P$ and reactive power $Q$ delivered to the grid can be expressed by [18], [19],

$$
\left\{\begin{array}{l}
P=\frac{V_{i n} V_{g}}{X_{l}} \sin \phi \approx \frac{V_{i n} V_{g}}{X_{l}} \phi \\
Q=\frac{V_{i n} V_{g} \cos \phi-V_{g}^{2}}{X_{l}} \approx \frac{\left(V_{i n}-V_{g}\right) V_{g}}{X_{l}}
\end{array}\right.
$$

where $X_{l}$ is the line reactance. Hence, the inverter voltage reference $v_{i n}^{*}$ can be obtained and it is controllable through the angle $\phi$ and the amplitude $V_{i n}$ by respectively regulating the active power and the reactive power. A droop controller can be given as,

$$
\left\{\begin{array}{ccc}
\phi & = & 0-k_{1}\left(P-P^{*}\right) \\
V_{i n} & = & V_{i n}^{*}-k_{2}\left(Q-Q^{*}\right)
\end{array}\right.
$$

in which ' $*$ ' donates the reference signal and $k_{1}, k_{2}$ can control the active and reactive power sharing between the PV inverters and the grid.

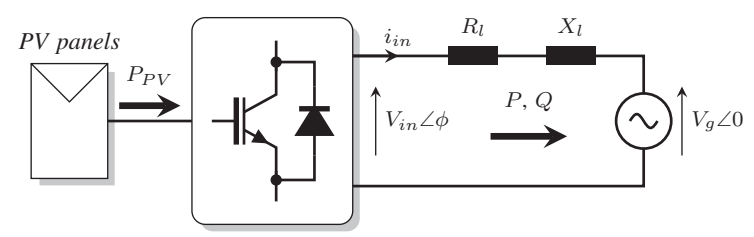

Fig. 5. Simplified single-phase grid-connected PV system.

This kind of control approach used to support the grid voltage is successfully tested in [18], [19], where the PV inverter is working as a shunt device and designed to compensate the grid voltage drops and the harmonic distortions. Usually, the shunt device is adopted to mitigate small voltage dips with a large inductance, which is the main weak point of such a control strategy because of the power loss and the size.

It is also worth to know that the active power delivered to the grid is limited by the inverter nominal current. Therefore, to avoid inverter shut-down because of the over-current protection, the PV panels should not operate in the maximum power point tracking (MPPT) mode depending on the solar irradiation, which can be illustrated in Fig. 6. It is shown that in grid faulty mode operation the active power should be limited in order to deliver the required reactive power without triggering the inverter over-current protection. Nevertheless, this aspect could be used for reactive power support, e.g. during the night when there is no solar irradiance [14].

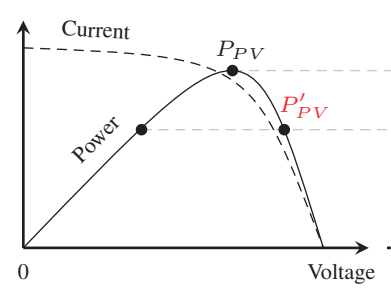

(a) PV characteristics

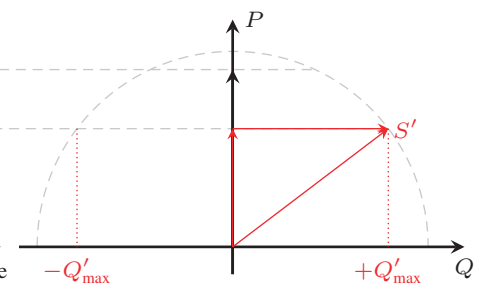

(b) P, Q diagram
Fig. 6. Limitation of active and reactive powers drawn from PV panels (black: normal MPPT operation, red: grid faulty mode operation).

Additionally, the double-frequency term present in the DC side (PV side) in single-phase systems will also have a negative impact on the control systems both under normal operation and in grid faulty mode operation [6]. Consequently, the design of the controllers, modulation techniques and gridinterfaced current filters $(L, L C$, or $L C L)$ should produce lower switching voltage stress and lower voltage ripple at the DC-link. 
Anyway, there are extensive control possibilities in singlephase grid-connected PV systems, which are able to meet the upcoming requirements defined in the grid codes. Regarding single-phase PV systems with grid support and LVRT functionalities, the control methods should be capable of providing accurate and appropriate references without exceeding DC nominal voltage, tripping the current protection due to constant active power delivery and failing to synchronize in compliance with these demands in the near future.

\section{GRID SyNCHRONIZATION TECHNIQUES FOR SINGLE-PHASE APPLICATIONS}

The synchronization algorithm plays a major role in the control of single-phase systems under grid faults. A good synchronization system should respond to a voltage drop immediately when a phase-to-ground fault occurs at PCC as shown in Fig. 3. Many synchronization methods are reported in recent literature [4], [6], [20]-[24], which can be divided into two category- mathematical analysis methods (synchronization based on Fourier analysis) and PLL-based methods. Notably, the main difference among various single-phase PLLs is the configuration of the phase detector, intuitively, being a simple sinusoidal multiplier [22], [23]. However, this process will produce a double-frequency term in a single-phase system.

A basic PLL structure which is commonly used in power systems is given in Fig. 7, which consists of a phase detector (PD), a proportional-integral (PI) based loop filter (LF) and a voltage-controlled oscillator ( $\mathrm{VCO}$ ). Thus, the small signal model of such a system can be given as,

$$
\frac{\hat{\Theta}(s)}{\Theta(s)}=\frac{K_{p} s+K_{i}}{s^{2}+K_{p} s+K_{i}},
$$

where $\hat{\Theta}, \Theta$ are the output and input phase respectively, and $K_{p}, K_{i}$ are the proportional and integral gains of the loop filter. The details of the PLL modeling can be found in [4]. From (6), the settling time can be given by $t_{s}=9.2 / K_{p}$ which is used to evaluate the performance of different PLLs in this paper.

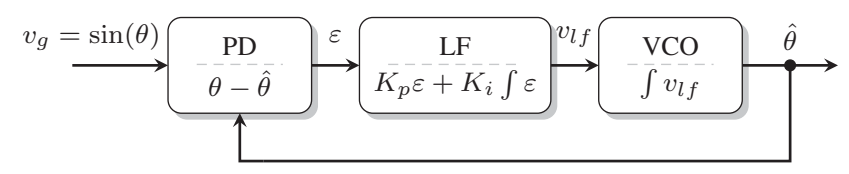

Fig. 7. Basic structure of a phase locked loop.

Applying the Park Transform to an OSG system is one way to extract the phase error. Hence, the task will be shifted to establish an OSG system. Such kind of PLLs are reported, like T/4 Delay PLL and Inverse Park Transform based PLL (IPT-PLL). Another possibility is to use adaptive filters which can self-adjust the output according to an error feedback loop. Two popular PLLs- the Enhanced PLL (EPLL) and the Second Order Generalized Integrator based PLL (SOGI-OSG), are based on the combinations of adaptive filters with a sinusoidal multiplier and an OSG system.

\section{A. T/4 Delay PLL}

This PLL approach takes the input voltage $v_{i}$ as the " $\alpha$ " component in a " $\alpha \beta$ " system, while the " $\beta$ " component can be obtained simply by introducing a phase shift of $\pi / 2 \mathrm{rad}$ with respect to the fundamental frequency of the input voltage. Thus the Park Transform can be used to detect the phase error, which is expressed as the following,

$$
\left[\begin{array}{l}
v_{d} \\
v_{q}
\end{array}\right]=\left[\begin{array}{cc}
\cos \hat{\theta} & \sin \hat{\theta} \\
-\sin \hat{\theta} & \cos \hat{\theta}
\end{array}\right]\left[\begin{array}{c}
v_{i} \\
v_{\beta}
\end{array}\right]=\left[\begin{array}{c}
V_{m} \sin (\Delta \theta) \\
-V_{m} \cos (\Delta \theta)
\end{array}\right] \approx\left[\begin{array}{c}
V_{m} \Delta \theta \\
-V_{m}
\end{array}\right],
$$

where $v_{i}=V_{m} \sin (\theta)=V_{m} \sin (\omega t+\phi)$, in which $V_{m}, \theta$, $\omega$ and $\phi$ are the amplitude, angle, frequency and phase angle of the input signal $v_{i}, \Delta \theta=\theta-\hat{\theta}$ is the detected phase error, and $\hat{\theta}$ is the locked phase angle.

Actually, the error $\Delta \theta$ is very small in steady state, and then we have the linearized equation shown in the very right side of (7). The structure of the T/4 Delay PLL is given in Fig. 8, where $T$ and $\omega_{0}$ are the period and nominal frequency of the input voltage $v_{i}$.

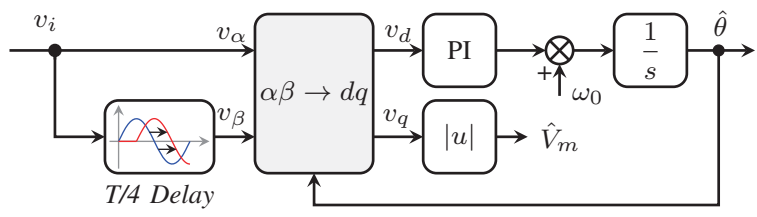

Fig. 8. Structure of T/4 Delay PLL for single-phase system.

\section{B. Enhanced PLL}

The Enhanced PLL (EPLL) introduced in [25], [29] is based on a simple adaptive filter (AF), which can refine the transfer function according to a feedback algorithm driven by an error signal. It can be used to track the input voltage in terms of amplitude $V_{m}$ and phase angle $\theta$.

The adaptive process is to minimize a so-called objective function by modifying the filter parameters. Then the amplitude is estimated. Define the objective function as,

$$
E\left(\hat{V}_{m}, \hat{\theta}\right)=\frac{1}{2} e^{2}=\frac{1}{2}\left(v_{i}-\hat{v}_{i}\right)^{2},
$$

in which $\hat{V}_{m}$ and $\hat{\theta}$ are the estimated amplitude and the locked phase of the input voltage, respectively. Then, the desired output of the filter can be expressed as $\hat{v}_{i}=\hat{V}_{m} \sin \hat{\theta}$.

In order to minimize the objective function, the popular least-mean-square (LMS) adaptive algorithm is used [30]. Then the following differential equation is obtained [25],

$$
\dot{\hat{V}}_{m}=-\mu \frac{\partial E\left(\hat{V}_{m}, \hat{\theta}\right)}{\partial \hat{V}_{m}}=\mu e \sin \hat{\theta} .
$$

where $\mu$ is the control parameter. Subsequently, the PD implementation of Enhanced PLL can be given in Fig. 9.

One important feature of EPLL concluded from the above discussion is that the output signal $\hat{v}_{i}$ is locked both in phase and in amplitude compared to the conventional PLL methods [29]. However, the performance, such as the speed 


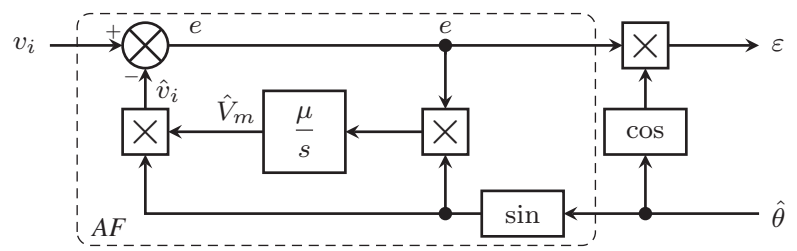

Fig. 9. Adaptive filter based phase detector of an enhanced PLL.

of the estimation process, is exclusively dependent on the control parameter $\mu$. By linearizing (9), this relationship can be described as [29],

$$
\frac{\hat{V}_{m}(s)}{V_{m}(s)}=\frac{1}{\tau s+1},
$$

where $\tau=2 / \mu$ is the time constant.

The response of such an adaptive filter in the EPLL system with different time constants is shown in Fig. 10. It is noticed that a large value of $\mu$ will make the estimated output signal coming to steady-state quickly, but it will have a high overshoot of frequency if $\mu$ is too large. The settling time of this system can approximately be calculated as: $4 \tau=8 / \mu$.
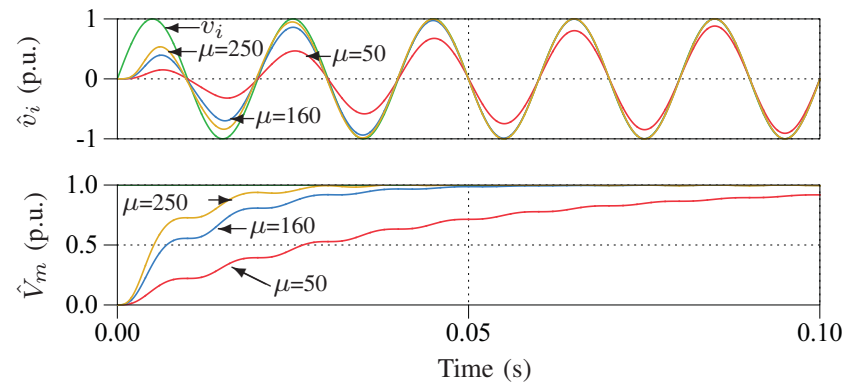

Fig. 10. Response of the adaptive filter of an enhanced PLL with different $\mu$ (different time constants, $\tau$ ).

\section{Second Order Generalized Integrator based PLL}

Another adaptive filtering based PLL solution is using second order generalized integrator (SOGI) to create the OSG system, commonly known as SOGI-OSG PLL [4], [26], [31]. The general OSG structure of SOGI-OSG PLL is depicted in Fig. 11, in which $\hat{\omega}$ is the estimated frequency of the input signal and $k_{e}$ is the control parameter.

Actually, the EPLL discussed above is using only oneweight adaptive filter, which is the simplest one. If two-weight adaptive filters are adopted in single-phase applications, it will present a better performance and it behaves like a "sinusoidal integrator" [4], [31], [32]. The transfer function of such kind of adaptive filter can be expressed as,

$$
G_{A F}(s)=\frac{s}{s^{2}+\hat{\omega}^{2}} .
$$

Multiplied by $\hat{\omega}$, it shares the transfer function of a secondorder generalized integrator in common [31], [33].

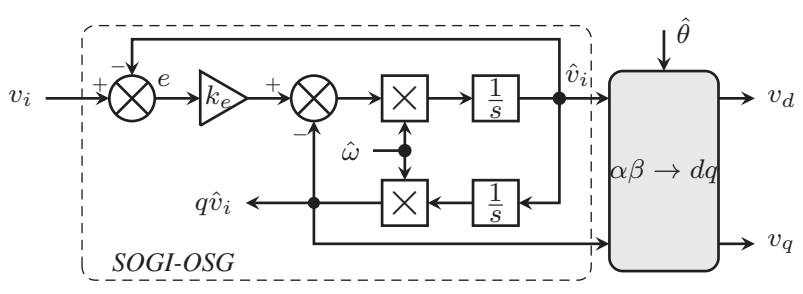

Fig. 11. Phase detector of the second order generalized integrator PLL.

Thus, referring to Fig. 11, the closed loop transfer functions of the SOGI-OSG PLL can be obtained as,

$$
\left\{\begin{array}{l}
\frac{\hat{v}_{i}(s)}{v_{i}(s)}=\frac{k_{e} \hat{\omega} s}{s^{2}+k_{e} \hat{\omega} s+\hat{\omega}^{2}}, \\
\frac{q \hat{v}_{i}(s)}{v_{i}(s)}=\frac{k_{e} \hat{\omega}^{2}}{s^{2}+k_{e} \hat{\omega} s+\hat{\omega}^{2}} .
\end{array}\right.
$$

The detailed derivation of these transfer functions can be found in [4] and [31]. In order to evaluate the performance of SOGIOSG PLL, the settling time is given as,

$$
t_{s}=\frac{9.2}{k_{e} \hat{\omega}} .
$$

\section{Comparison of the PLLs}

For the comparison of the above synchronization solutions, faulty grid cases are simulated and verified experimentally with the parameters shown in TABLE I. The results shown in Fig. 12 and Fig. 13 are obtained when the grid has a 0.45 p.u. voltage sag. More comparisons of these PLLs in terms of the settling time and the overshoot of frequency are provided in TABLE II where different changes are done like frequency jump and phase jump.

TABLE I

Simulation Parameters for All Tests

\begin{tabular}{c|c}
\hline Nominal Voltage Amplitude & $V_{m}=230 \sqrt{2} \mathrm{~V}$ \\
\hline Nominal Voltage Frequency & $\omega_{0}=100 \pi \mathrm{rad} / \mathrm{s}$ \\
\hline Grid Impedance & $Z_{g}=0.1+0.65 j \Omega$ \\
\hline PI Controller for all PPLs & $K_{p}=0.3, K_{i}=13.6$ \\
\hline Control Parameters & $\mu=250, k_{e}=\sqrt{2}$ \\
\hline
\end{tabular}

TABLE II

COMPARISON OF THE PLLS

\begin{tabular}{c|ccc}
\hline & T/4 Delay & EPLL & SOGI-OSG \\
\hline \multirow{2}{*}{ Voltage Sag (0.45 p.u.) } & $4.7 \mathrm{~ms}$ & $7.8 \mathrm{~ms}$ & $8 \mathrm{~ms}$ \\
& $0.26 \mathrm{~Hz}$ & $0.91 \mathrm{~Hz}$ & $0.62 \mathrm{~Hz}$ \\
\hline \multirow{2}{*}{ Phase Jump $\left(+90^{\circ}\right)$} & $75 \mathrm{~ms}$ & $120 \mathrm{~ms}$ & $72 \mathrm{~ms}$ \\
& $16.1 \mathrm{~Hz}$ & $16 \mathrm{~Hz}$ & $19.1 \mathrm{~Hz}$ \\
\hline \multirow{2}{*}{ Frequency Jump $(+1 \mathrm{~Hz})$} & Oscillate & $186 \mathrm{~ms}$ & $111 \mathrm{~ms}$ \\
& $(-1.2,1.2) \mathrm{Hz}$ & $8.4 \mathrm{~Hz}$ & $10.4 \mathrm{~Hz}$ \\
\hline OSG Mechanism & $\sqrt{ }$ & $\times$ & $\sqrt{ }$ \\
\hline Complexity & $\star$ & $\star \star$ &
\end{tabular}




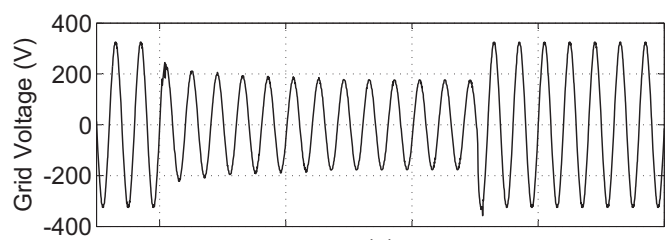

(a)

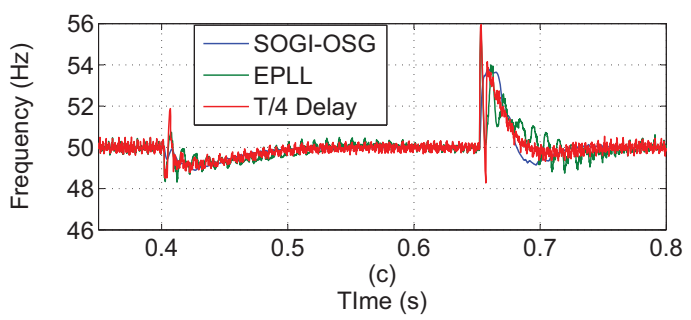

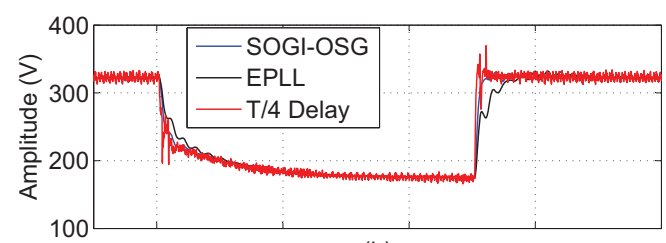

(b)

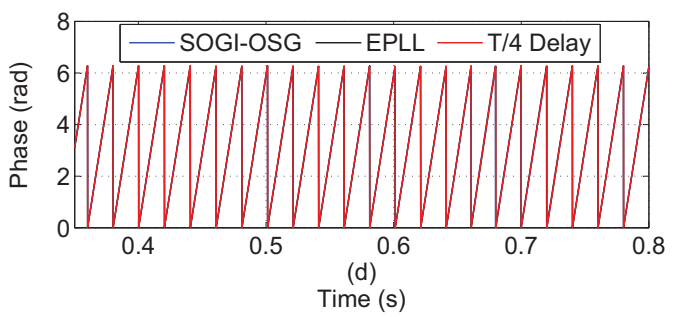

Fig. 12. Comparison of the three selected PLLs under a grid voltage sag ( 0.45 p.u.).

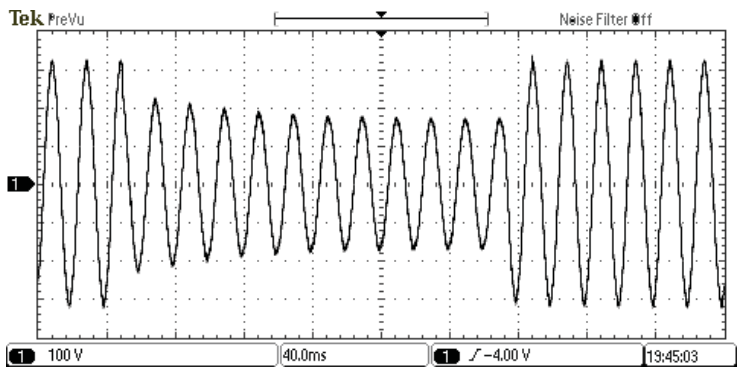

(a) Grid Voltage $[100 \mathrm{~V} / \mathrm{div}]$

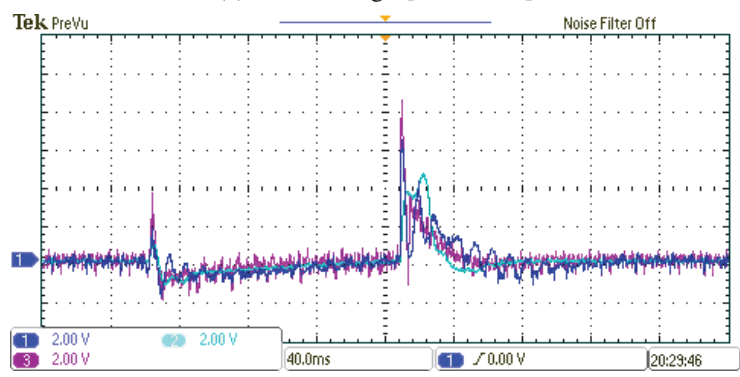

(c) Frequency Error [2 Hz/div]

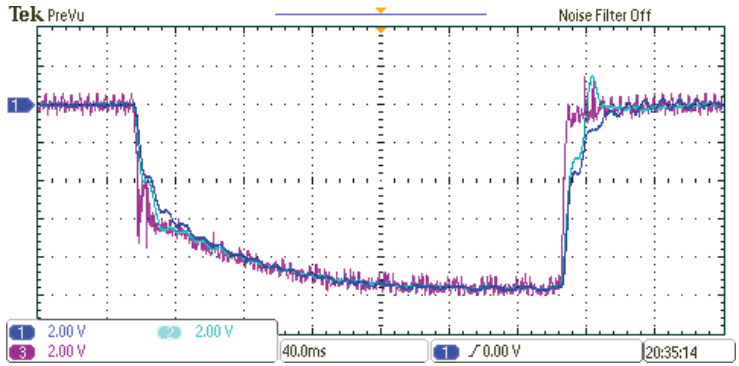

(b) Amplitude Error [30 V/div]

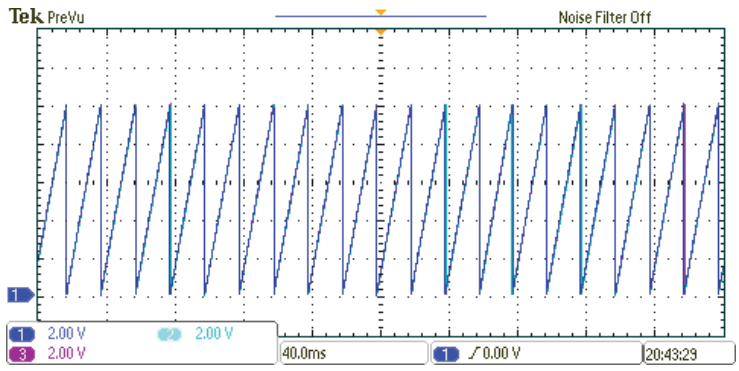

(d) Phase $[2 \pi \mathrm{rad} /(5$ divs $)]$

Fig. 13. Experimental results of the three selected PLLs under a grid voltage sag ( 0.45 p.u. $)$ : 1 . Enhanced PLL; 2 . Second order generalized integrator based PLL; 3. T/4 Delay based PLL, $[t=40 \mathrm{~ms} / \mathrm{div}]$.

As it can be seen in the results, the performances of these PLL methods are not very good during the voltage sag. The T/4 Delay method can follow the amplitude change quickly (a quarter of the grid frequency), while it can not be a good synchronization technique when the grid is subjected to frequency variations. Although, the attractiveness of an EPLL is that it can estimate both the amplitude and the frequency of the input voltage without doubling the input frequency oscillations. This kind of PLL method presents a slow transient variation as shown in Fig. 12 and Fig. 13. This variation demonstrates how the adaptive filter minimizes the objective function. With respect to the control of singlephase systems, the EPLL method is not suitable for calculating active and reactive power, but it could be used to control the instantaneous power [28]. The SOGI-OSG PLL can track the input voltage with better performance compared to $\mathrm{T} / 4$ Delay PLL and EPLL especially when the grid presents a frequency variation/jump. It is concluded that, together with fast detection methods, the SOGI-OSG method is the best candidate for single-phase applications.

\section{System Ride-Through Operation}

A simple case is examined by simulation under a voltage sag in order to give a basic demonstration about single-phase systems under grid faults and it is also validated experimentally. This system consists of a DC source and a single-phase full bridge inverter as shown in Fig. 3. An $L C$ filter is used with the parameters: $L=3.6 \mathrm{mH}, C=2.35 \mu \mathrm{F}$ and it is 

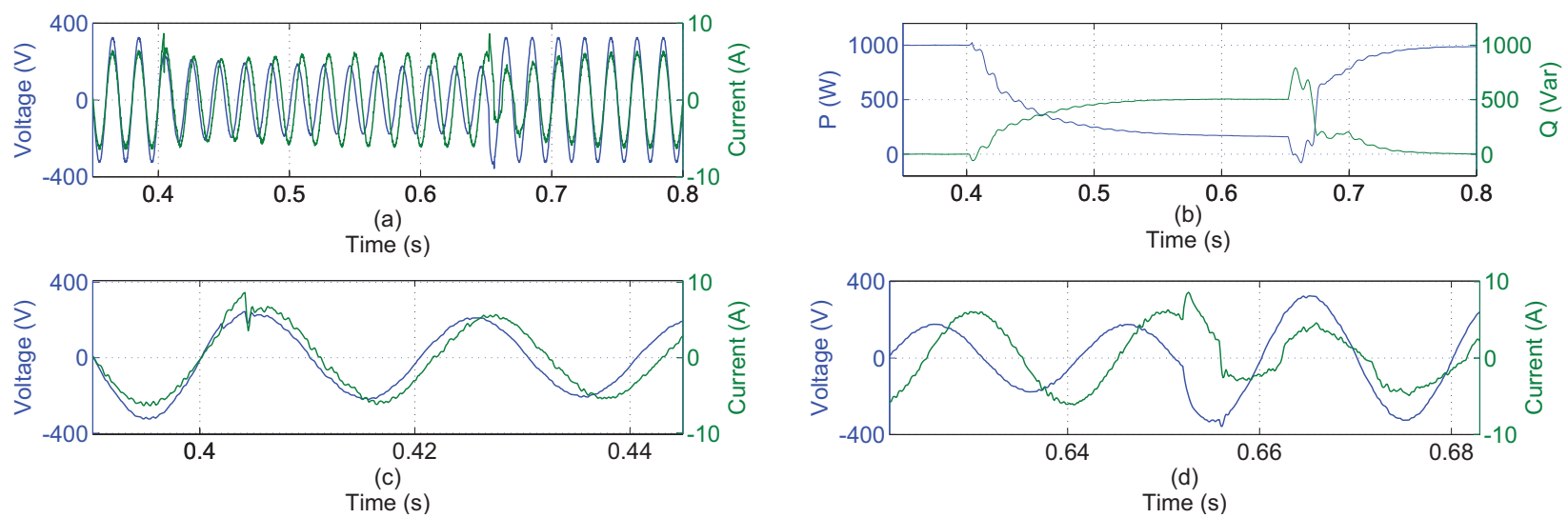

Fig. 14. Simulation results for a single-phase system under voltage dip using PR controller and SOGI-OSG PLL synchronization method: (a) grid voltage and current; (b) active and reactive power; (c) transient grid voltage and current (voltage drop); (d) transient grid voltage and current (voltage recovery).

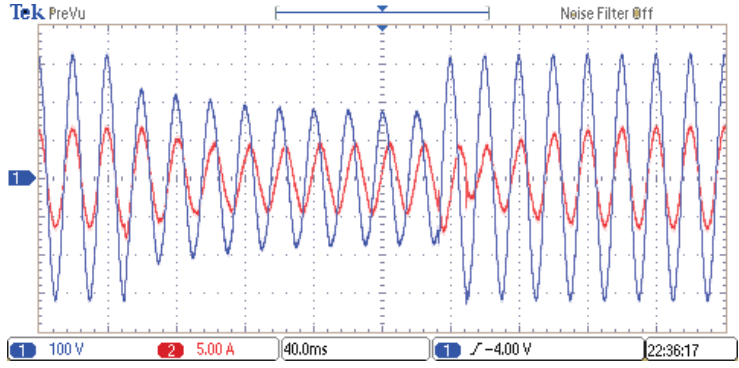

(a) Grid Voltage $[100 \mathrm{~V} / \mathrm{div}]$ and Current $[5 \mathrm{~A} / \mathrm{div}]$

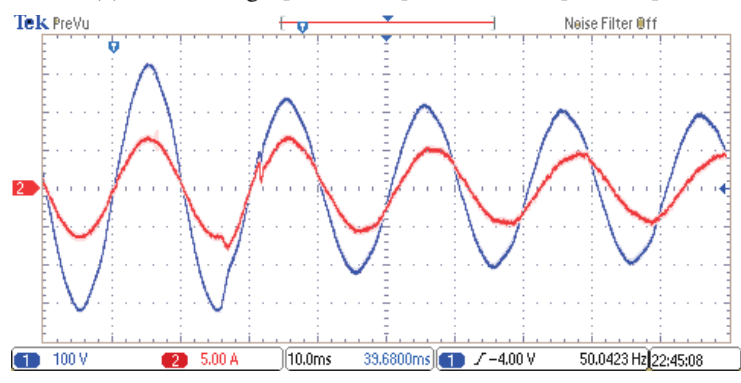

(c) Grid Voltage $[100 \mathrm{~V} /$ div $]$ and Current [5 A/div]

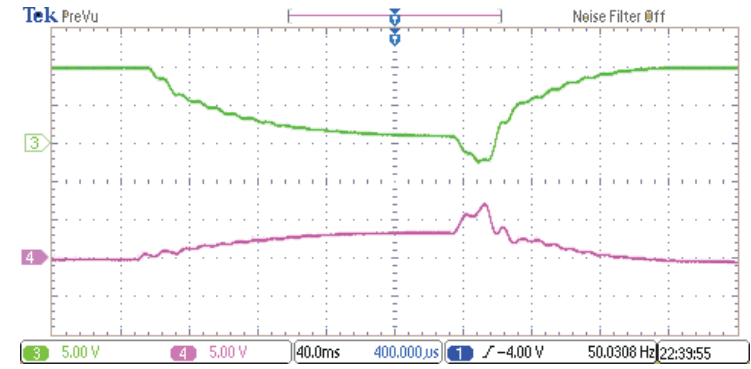

(b) Active Power [500 W/div] and Reactive Power [500 Var/div]

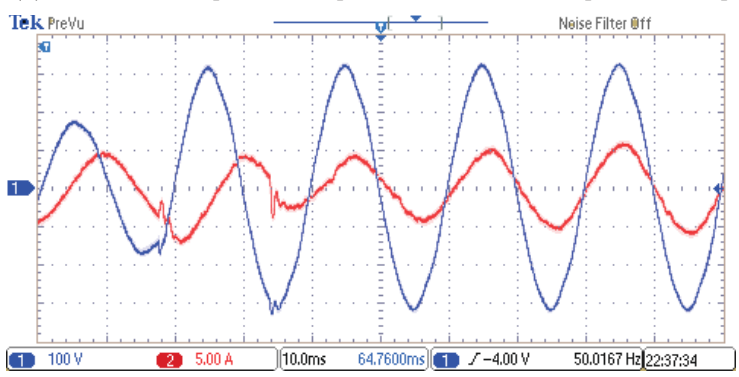

(d) Grid Voltage [100 V/div] and Current [5 A/div]

Fig. 15. Experimental results of a single-phase system under voltage dip using PR controller and SOGI-OSG PLL synchronization method: 1. grid voltage; 2. grid current; 3. active power; 4. reactive power, $[t=40 \mathrm{~ms} / \mathrm{div}]$.

connected to the grid through a transformer with the leakage inductance of $L_{T}=4 \mathrm{mH}$. The nominal grid parameters are shown in TABLE I.

Referring to Fig. 4, a PR controller with harmonics compensation is used as the current controller and, based on the comparison in $\S \mathrm{IV}$, the SOGI-OSG PLL is adopted to detect the grid fault and to synchronize with the grid. The parameters of the PI controller for active power are $K_{p p}=1.5$ and $K_{p i}=$ 52 , while the parameters for reactive power are $K_{q p}=1$ and $K_{q i}=50$. The results of this case are shown in Fig. 14 and Fig. 15.

A 0.45 p.u. voltage sag is generated by short-circuiting a series resistance. It is seen that, during the fault, the system is controlled to limit the active power output without tripping current protection. Practically, the active power could be controlled by regulating the maximum power point. The single-phase system can provide reactive power according to the depth of the voltage sag in order to support the grid, as shown in Fig. 14 and Fig. 15, and it can do it fast. The reactive power is injected into the utility grid until the grid voltage recovers to 0.9 p.u., and the current and active power output goes back to the normal values.

\section{CONCLUSION}

This paper presents the future requirements for singlephase grid-connected PV systems under grid faults. It can be concluded that the future grid-connected PV systems will be more active and more "smart", which means the future gridconnected PV systems should have some ancillary functionalities as the conventional power plants do in the presence of 
an abnormal grid condition.

Different control strategies of such kind of single-phase PV systems under grid faults are discussed and it is concluded that the control possibilities play an important role in singlephase applications, since they are responsible not only for the power quality and protection issues but also for the upcoming ancillary requirements. It can also be concluded that the single-phase PV inverters are ready to provide grid support. Selected detection and synchronization techniques are also compared in the case of grid fault conditions. The comparison demonstrates that the SOGI-OSG based PLL technique might be the promising candidate for single-phase systems under grid faults. Furthermore, an other adaptive filtering based PLL (EPLL) shows also a good performance under a voltage sag, but it has transient variations.

A single-phase case is studied and tested experimentally at the end of this paper in order to demonstrate the overall system performance under grid faulty conditions and it shows satisfactory performance.

\section{REFERENCES}

[1] “EPIA-Market Report, 2011,” EPIA, Tech. Rep., Jan. 2012. [Online]. Available: http://www.epia.org/

[2] F. Iov, A. D. Hansen, P. E. Sørensen, and N. A. Cutululis, "Mapping of grid faults and grid codes," Ris $\varnothing$ National Laboratory, Technical University of Denmark, Tech. Rep., 2007.

[3] E. ON GmbH, "Grid Code - High and Extra High Voltage." [Online]. Available: http://www.eon-netz.com/

[4] R. Teodorescu, M. Liserre, and P. Rodríguez, Grid Converters for Photovoltaic and Wind Power Systems. John Wiley \& Sons, 2011.

[5] F. Blaabjerg, M. Liserre, and K. Ma, "Power electronics converters for wind turbine," IEEE Trans. Ind. Appl., vol. 48, no. 2, pp. 708-719, Mar--Apr. 2012

[6] F. Blaabjerg, R. Teodorescu, M. Liserre, and A. Timbus, "Overview of control and grid synchronization for distributed power generation systems," IEEE Trans. Ind. Electron., vol. 53, no. 5, pp. 1398-1409, Oct. 2006.

[7] S. B. Kjaer, J. K. Pedersen, and F. Blaabjerg, "A review of single-phase grid-connected inverters for photovoltaic modules," IEEE Trans. Ind. Appl., vol. 41, no. 5, pp. 1292-1306, Sept.-Oct. 2005.

[8] E. J. Coster, J. M. A. Myrzik, B. Kruimer, and W. L. Kling, "Integration issues of distributed generation in distribution grids," Proceedings of the IEEE, vol. 99 , no. 1 , pp. $28-39$, Jan. 2011.

[9] G. M. S. Islam, A. Al-Durra, S. M. Muyeen, and J. Tamura, "Low voltage ride through capability enhancement of grid connected large scale photovoltaic system," in Proc. of IECON'11, pp. 884-889, Nov. 2011.

[10] M. Braun, G. Arnold, and H. Laukamp, "Plugging into the zeitgeist," IEEE Power Energy Mag., vol. 7, no. 3, pp. 63-76, 2009.

[11] Comitato Elettrotecnico Italiano, "CEI 0-21: Reference technical rules for connecting users to the active and passive LV distribution companies of electricity," 2011. [Online]. Available: http://www.ceiweb.it/

[12] C. H. Benz, W. Franke, and F. W. Fuchs, "Low voltage ride through capability of a $5 \mathrm{~kW}$ grid-tied solar inverter," in Proc. of EPE/PEMC, pp. T12-13-T12-20, Sept. 2010.

[13] K. Fujii, N. Kanao, T. Yamada, and Y. Okuma, "Fault ride through capability for solar inverters," in Proc. of EPE/PEMC, pp. 1-9, 2011.

[14] A. Marinopoulos, F. Papandrea, M. Reza, S. Norrga, F. Spertino, and R. Napoli, "Grid integration aspects of large solar PV installations: LVRT capability and reactive power/voltage support requirements," in Proc. of IEEE Trondheim PowerTech, pp. 1-8, June 2011.

[15] C. Photong, C. Klumpner, and P. Wheeler, "A current source inverter with series connected ac capacitors for photovoltaic application with grid fault ride through capability," in Proc. of IECON'09, pp. 390-396, Nov. 2009.

[16] M. Saitou and T. Shimizu, "Generalized theory of instantaneous active and reactive powers in single-phase circuits based on hilbert transform," in Proc. of PESC'02, vol. 3, pp. 1419-1424, 2002.
[17] M. Prodanovic, K. De Brabandere, J. Van Den Keybus, T. Green, and J. Driesen, "Harmonic and reactive power compensation as ancillary services in inverter-based distributed generation," IET Gener. Transm. Distrib., vol. 1, no. 3, pp. 432-438, May 2007.

[18] R. A. Mastromauro, M. Liserre, T. Kerekes, and A. Dell'Aquila, "A single-phase voltage-controlled grid-connected photovoltaic system with power quality conditioner functionality," IEEE Trans. Ind. Electron., vol. 56, no. 11, pp. 4436-4444, Nov. 2009.

[19] J. C. Vasquez, R. A. Mastromauro, J. M. Guerrero, and M. Liserre, "Voltage support provided by a droop-controlled multifunctional inverter,' IEEE Trans. Ind. Electron., vol. 56, no. 11, pp. 4510-4519, Nov. 2009.

[20] R. M. Santos Filho, P. F. Seixas, P. C. Cortizo, L. A. B. Torres, an A. F. Souza, "Comparison of three single-phase PLL algorithms for UPS applications," IEEE Trans. Ind. Electron., vol. 55, no. 8, pp. 2923-2932, Aug. 2008.

[21] A. Nicastri and A. Nagliero, "Comparison and evaluation of the PLL techniques for the design of the grid-connected inverter systems," in Proc. of ISIE'10, pp. 3865-3870, July 2010.

[22] A. Nagliero, R. A. Mastromauro, M. Liserre, and A. Dell'Aquila, "Monitoring and synchronization techniques for single-phase PV systems," in Proc. of SPEEDAM, pp. 1404-1409, June 2010.

[23] S. Golestan, M. Monfared, F. Freijedo, and J. Guerrero, "Design and tuning of a modified power-based pll for single-phase grid-connected power conditioning systems," IEEE Trans. Power Electron., vol. 27, no. 8, pp. 3639-3650, Aug. 2012

[24] L. N. Arruda, S. M. Silva, and B. J. C. Filho, "PLL structures for utility connected systems," in Proc. of IEEE-IAS Annu. Meeting, vol. 4, pp. 2655-2660, 2001.

[25] M. K. Ghartemani, S. A. Khajehoddin, P. K. Jain, and A. Bakhshai, "Problems of startup and phase jumps in PLL systems," IEEE Trans. Power Electron., vol. 27, no. 4, pp. 1830-1838, Apr. 2012

[26] P. Rodríguez, A. Luna, R. Munoz-Aguilar, F. Corcoles, R. Teodorescu, and F. Blaabjerg, "Control of power converters in distributed generation applications under grid fault conditions," in Proc. of IEEE ECCE'11, pp. 2649-2656, Sept. 2011.

[27] B. Bahrani, A. Rufer, S. Kenzelmann, and L. A. C. Lopes, "Vector control of single-phase voltage-source converters based on fictive-axis emulation," IEEE Trans. Ind. Appl., vol. 47, no. 2, pp. 831-840, Mar.Apr. 2011.

[28] S. A. Khajehoddin, M. Karimi Ghartemani, A. Bakhshai, and P. Jain, "A power control method with simple structure and fast dynamic response for single-phase grid-connected DG systems," IEEE Trans. Power Electron., vol. PP, no. 99, 2012.

[29] M. Karimi-Ghartemani and M. R. Iravani, "A new phase-locked loop (PLL) system," in Proc. of IEEE MWSCAS, vol. 1, pp. 421-424, 2001

[30] Paulo S. R. Diniz, Adaptive Filtering: Algorithms and Practical Implementation. Springer, 2010

[31] M. Ciobotaru, R. Teodorescu, and F. Blaabjerg, "A new single-phase PLL structure based on second order generalized integrator," in Proc. of PESC'06, pp. 1-6, June 2006.

[32] S. Douglas and T.-Y. Meng, "A nonlinear error adaptive notch filter for separating two sinusoidal signals," in Proc. of ASILOMAR, vol. 2, pp. 673-677, Nov. 1991

[33] X. Yuan, W. Merk, H. Stemmler, and J. Allmeling, "Stationary-frame generalized integrators for current control of active power filters with zero steady-state error for current harmonics of concern under unbalanced and distorted operating conditions," IEEE Trans. Ind. Appl., vol. 38, no. 2, pp. 523 -532, Mar./Apr. 2002.

[34] A. Camacho, M. Castilla, J. Miret, J. Vasquez, and E. Alarcon-Gallo, "Flexible voltage support control for three phase distributed generation inverters under grid fault," IEEE Trans. Ind. Electron., vol. PP, no. 99, 2012.

[35] S. M. Silva, B. M. Lopes, B. J. C. Filho, R. P. Campana, and W. C. Bosventura, "Performance evaluation of PLL algorithms for single-phase grid-connected systems," in Proc. of IEEE-IAS Annu. Meeting, vol. 4, pp. 2259-2263, Oct. 2004.

[36] M. Z. C. Wanik, A. Mohamed, A. F. A. Kadir, and I. Erlich, "Low voltage ride through capability of fuel cell generation system connected to low voltage network," in Proc. of IEEE CET, pp. 369-373, June 2011.

[37] M. Bollen, Understanding power quality problems: voltage sags and interruptions. IEEE Press, 2000.

[38] Y. Yang and F. Blaabjerg, "Synchronization in single-phase gridconnected photovoltaic systems under grid faults," in Proc. of PEDG'12, pp. 476-482, to be published, 2012 